\title{
CARACTERIZAÇÃO SOCIOECONÔMICO CULTURAL E PROCEDIMENTOS PÓS- COLHEITA DE PLANTAS MEDICINAIS COMERCIALIZADAS POR RAIZEIROS EM QUATRO CIDADES DO RIO GRANDE DO NORTE
}

\author{
A. C. de ARAÚJO ${ }^{1 *}$, A. P. FERNANDES ${ }^{1}$, C. F. LIRA ${ }^{1}$, A. C. de ARAÚJO ${ }^{2}$ \\ ${ }^{1}$ Escola Agrícola de Jundiaí/Universidade Federal do Rio Grande do Norte, ${ }^{2}$ Centro de Ciências \\ Agrárias/Universidade Federal da Paraíba \\ afranio@eaj.ufrn.br*
}

Submetido 21/01/2013 - Aceito 20/11/2017

DOI: $10.15628 /$ holos.2017.1226

\section{RESUMO}

Objetivou-se com este trabalho estabelecer o perfil socioeconômico cultural de raizeiros e avaliar os procedimentos pós-colheita adotados para plantas medicinais comercializadas no estado do Rio Grande do Norte. $O$ estudo foi realizado, nas cidades de Natal, Santana do Matos, Ipanguaçu e Lagoa de Pedras onde foram entrevistados, no total, 40 raizeiros. Foram utilizados formulários pré-estruturados nos quais constavam questões relacionadas a aspectos sociais, culturais e econômicos dos raizeiros e procedimentos pós-colheita das plantas medicinais comercializadas nestes municípios. Constatou-se que a maior parte dos entrevistados era parda, católica, havia cursado parcialmente o ensino fundamental e a renda mensal obtida com a venda das plantas medicinais era superior a um salário mínimo. Os procedimentos póscolheita e o armazenamento de plantas medicinais adotados mostraram-se inadequadas por comprometerem a qualidade do produto.

PALAVRAS-CHAVE: Etnoconhecimento, medicina natural, mercados populares, beneficiamento.

\section{CULTURAL, ECONOMIC AND SOCIAL CHARACTERIZATION OF HERB SELLERS AND POSTHARVEST PROCEDURES OF MEDICINAL PLANTS COMMERCIALIZED IN FOUR CITIES IN RIO GRANDE DO NORTE, BRAZIL}

\begin{abstract}
The aim of this work was to establish the cultural, social and economical profile of medicinal herb sellers, as well as to survey the postharvest procedures of medicinal plants sold in open-air markets in Rio Grande do Norte State. In four cities, Natal, Santana do Matos, Ipanguaçu and Lagoa de Pedras, were interviewed, 40 herb sellers. Social, economic and cultural aspects were evaluated, as
\end{abstract}

well as, some postharvest procedures adopted for the medicinal plants were evaluate. Most of interviewed people were brown, catholic, received more than one minimum wage per month and were alphabetized. The postharvest and storage procedures adopted by the herb sellers showed unsuitable because the plants could be damaged.

KEYWORDS: Traditional knowledge, natural medicine, folk markets, processing. 


\section{INTRODUÇÃO}

O uso de plantas medicinais no tratamento de enfermidades humanas é antigo e tem aumentado nos últimos anos, o que vem se refletindo em uma grande expansão desse mercado (FREITAS et al., 2012). As dificuldades de acesso ao sistema público de saúde ou mesmo a busca por meios mais naturais para o tratamento de doenças vêm colocando as plantas medicinais como uma alternativa cada vez mais presente entre populações (DANTAS et al., 2008). O aumento do interesse da humanidade pelas plantas medicinais e produtos delas derivados, iniciou-se de modo substancial particularmente a partir da década de 90 acarretou a abertura de mercados nacionais e mundiais de fitoterápicos e plantas bioativas (ETHUR et al., 2011).

O conhecimento tradicional é "um corpo de conhecimento construído por um grupo de pessoas através de sua vivência em contato próximo com a natureza por várias gerações". Engloba um sistema de classificação organizado a partir de um conjunto de observações empíricas sobre o ambiente local e um sistema de auto-manejo que coordena o uso dos recursos (PNUMA, 2002). O conhecimento dos inúmeros recursos da flora medicinal brasileira se perpetua ao longo das gerações. Este saber, fruto da observação da natureza, vem sendo, transmitido, em geral, de modo verbal e não escrito, por comunidades tradicionais, mas persiste e é, muitas vezes, incorporado à ciência (ARAÚJO et al., 2009).

A farmacopeia popular brasileira é bastante diversificada e se baseia, principalmente, em plantas medicinais. Resulta da miscigenação cultural envolvendo povos africanos, europeus e indígenas. Inclui, além de espécies nativas, naturalmente presentes de modo abundante na flora brasileira como espécies exóticas introduzidas por escravos e colonizadores (MELO et al., 2007).

Grande parte das plantas medicinais consumidas pelas populações são comercializadas em feiras livres, locais que, em geral, não apresentam condições higiênicas adequadas do ponto de vida médico-sanitário e onde não há fiscalização por parte dos órgãos públicos (ROCHA et al., 2010). No Brasil o comércio destas plantas é muito forte e comum em todas as cidades, principalmente em mercados a céu aberto (ALVES et al., 2007). A comercialização de plantas medicinais nestes ambientes ocorre, na maioria das vezes, como consequência do desemprego e inexistência de outras alternativas de renda. Desta forma, a qualidade do produto pode ser afetada pela falta de cuidados com o produto, o que acaba provocando a perda dos princípios ativos e, consequentemente a diminuição de sua eficácia. A atividade pode envolver pessoas que não conhecem suficientemente as aplicações, modos corretos de uso e interações entre os princípios ativos de plantas de espécies distintas (ETHUR et al., 2011). Por outro lado, os mercados populares são importantes na manutenção e difusão do conhecimento empírico acerca das plantas medicinais, ajudando, assim, na manutenção do conhecimento popular das espécies mais usadas (MONTEIRO et al., 2010).

Após a colheita, as plantas medicinais podem seguir três diferentes caminhos: (1) uso direto do material fresco, (2) extração dos princípios ativos do material fresco e (3) secagem para comercialização. Por permitir a preservação do material, que poderá ser utilizado por um maior período, este último destino requer maior atenção. A qualidade das plantas é influenciada diretamente pelos processos de secagem, estabilização e armazenamento. O beneficiamento de 
plantas medicinais varia conforme a forma de comercialização, no entanto, em sua maioria, o produto é comercializado na forma desidratada (MARTINS, 2003).

A pós-colheita é o conjunto de técnicas que visa preservar a qualidade do produto agrícola e aumentar o tempo de conservação do produto. A desidratação resulta na redução da atividade enzimática, o que aumenta o período de conservação. A redução do teor de água resulta no aumento do percentual de princípio ativos (MAGALHÃES, 1997). As perdas dos princípios ativos que ocorrem com a pós-colheita devem-se a vários fatores, dentre eles destacam-se hidrólise, degradação pela luz, degradação enzimática, oxidação, fermentação, calor e contaminação microbiológica (SILVA et al. 1999).

Objetivou-se com este trabalho estabelecer o perfil socioeconômico cultural e avaliar os procedimentos pós-colheita adotados por raizeiros para as plantas medicinais comercializadas em feiras e mercados ao ar livre de quatro cidades do Rio Grande do Norte.

.informações

\section{MATERIAL E MÉTODOS}

O Rio Grande do Norte tem uma população de 3.137.541 habitantes (IBGE, 2010) e um território de, aproximadamente, $52.796,791 \mathrm{~km}^{2}$. O estudo foi realizado no período de janeiro a março de 2011, com raizeiros que comercializam plantas medicinais nas cidades de Natal, Santana do Matos, Ipanguaçu e Lagoa de Pedras (Figura 1). Foram visitadas bancas de venda de plantas medicinais alocadas nos mercados centrais e em outras imediações destas cidades, tendo sido entrevistados, em cada cidade, 10 raizeiros que se dispuseram a colaborar com trabalho, 0 que supera $80 \%$ dos total de raizeiros distribuídos na área de estudo. As informações foram obtidas através de entrevistas que ocorreram no próprio ponto de trabalho dos entrevistados em momentos de pouco movimento.

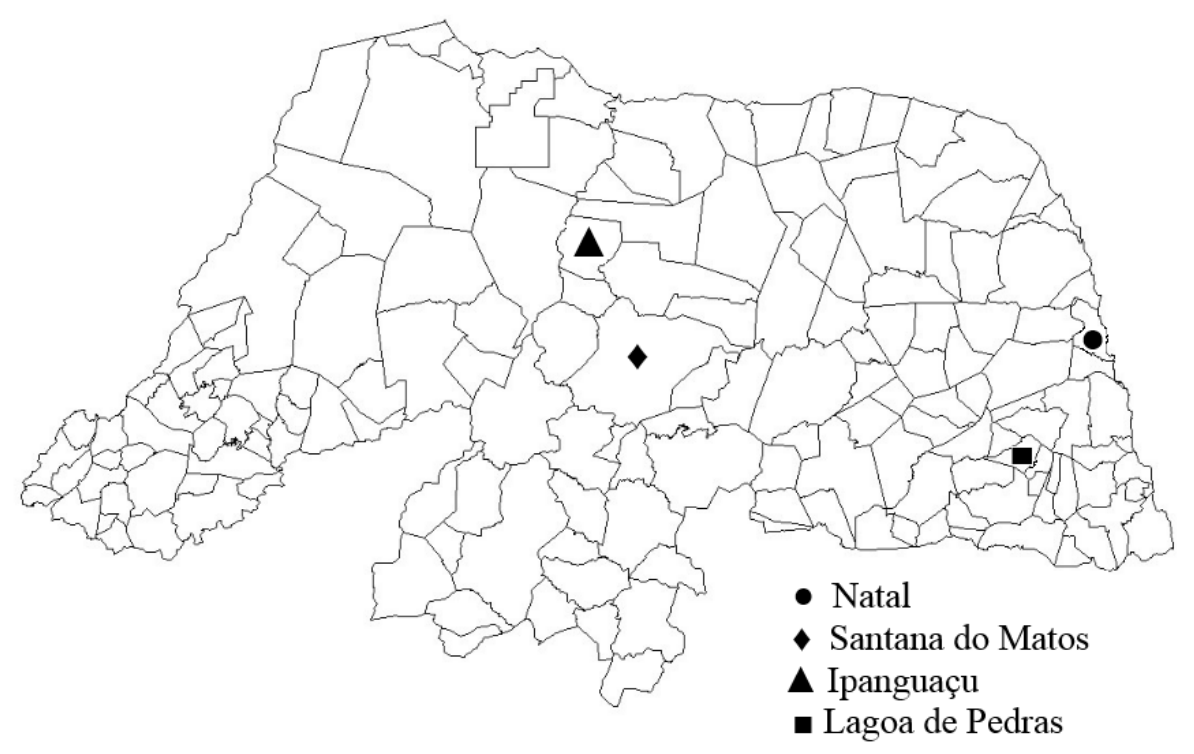

Figura 1. Localização dos municípios de Natal, Santana do Matos, Ipanguaçu e Lagoa de Pedras no Estado do Rio Grande do Norte. Macaíba, 2011. 
De modo a não ocupar tendo demasiado dos entrevistados, ao invés de utilizar-se questões abertas elaboradas in loco, foram utilizados formulários pré-estruturados nos quais constaram questões objetivas relacionadas à religião (espiritismo, evangelismo, catolicismo, sem religião), forma de aquisição do conhecimento acerca das plantas medicinais (pais e avós, livros e revistas, amigos, outros), renda mensal (menos de um salário mínimo, um salário mínimo, mais de um salário mínimo), estado civil (casado, solteiro), raça (brancos, negros e pardos), tempo de trabalho com as plantas (de um a cinco anos, de seis a dez anos, de onze a quinze anos, de dezesseis a vinte anos, mais de vinte anos), escolaridade (analfabeto ou semianalfabeto, ensino fundamental incompleto, ensino fundamental completo, ensino médio incompleto, ensino médio completo, ensino superior incompleto, ensino superior completo), local (cidade) de trabalho e residência e cidade de origem (naturalidade). As variáveis utilizadas para a avaliação dos procedimentos pós-colheita das plantas medicinais adotadas pelos raizeiros foram: forma de secagem das plantas (exposição direta ao sol, alternância sol/sombra, sombra), tempo de secagem das plantas (de dois a três dias, de dois a quatro dias), local de secagem das plantas (pendurada na banca de venda, no balcão da banca de venda, sobre um papelão, sobre uma lona plástica, sobre o piso), tempo de armazenamento após a secagem (até um ano, mais de ano), possibilidade de contato entre plantas de espécies diferentes quando armazenadas (há contato, não há contato) e forma como são guardadas as plantas após o expediente de trabalho (caixas de madeira, sacos plásticos, caixas de papelão, caixas plásticas e sem proteção).

\section{RESULTADOS E DISCUSSÃO}

Dentro do espaço amostral formado pelas quatro cidades nas quais o estudo foi realizado, observou-se que os católicos são a maioria no ramo da comercialização informal e a céu aberto de plantas medicinais e ervas aromáticas (85,0 \%), seguidos dos sem religião (7,5 \%) (Figura 2). A fração católica dos brasileiros gira em torno de $65 \%$ (IBGE, 2010) e a imensa maioria dos antigos "mateiros", detentores do conhecimento das plantas no Brasil eram seguidores desta religião, inclusive os descendentes de povos indígenas e de escravos de origem africana, daí a forte relação entre raizeiros e o catolicismo.

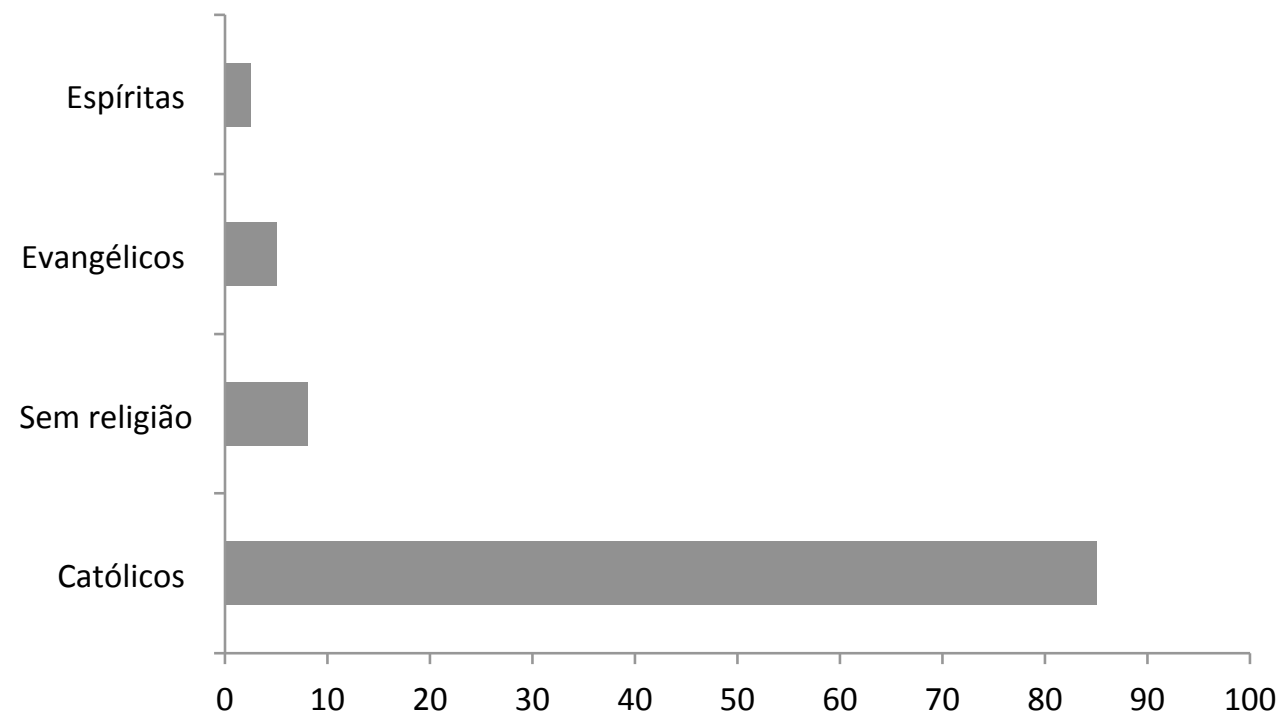


Figura 2. Religião dos raizeiros. Macaíba, 2011.

No tocante à escolaridade, à época em que a pesquisa foi realizada, $40,0 \%$ dos entrevistados haviam concluído o ensino fundamental e apenas 10,0 \% haviam concluído o ensino médio (Figura 3). Declararam-se analfabetos ou semianalfabetos $10,0 \%$ dos indivíduos. 0 percentual de analfabetos é relativamente baixo quando comparado com os encontrados por Dantas e Guimarães (2006) em Campina Grande, PB, onde o índice de analfabetismo entre os raizeiros chegou a 55,8 \% e por Araújo et al. (2009) em Maceió, AL, quando o índice chegou a $30,0 \%$. No entanto, um percentual de iletrados que gira em torno de $10 \%$ não pode deixar de ser considerado elevado em um país que almeja atingir a condição "desenvolvido". Analfabetismo leva à falta de opção de trabalho e o comércio informal de plantas medicinais no Brasil está fortemente relacionado ao desemprego.

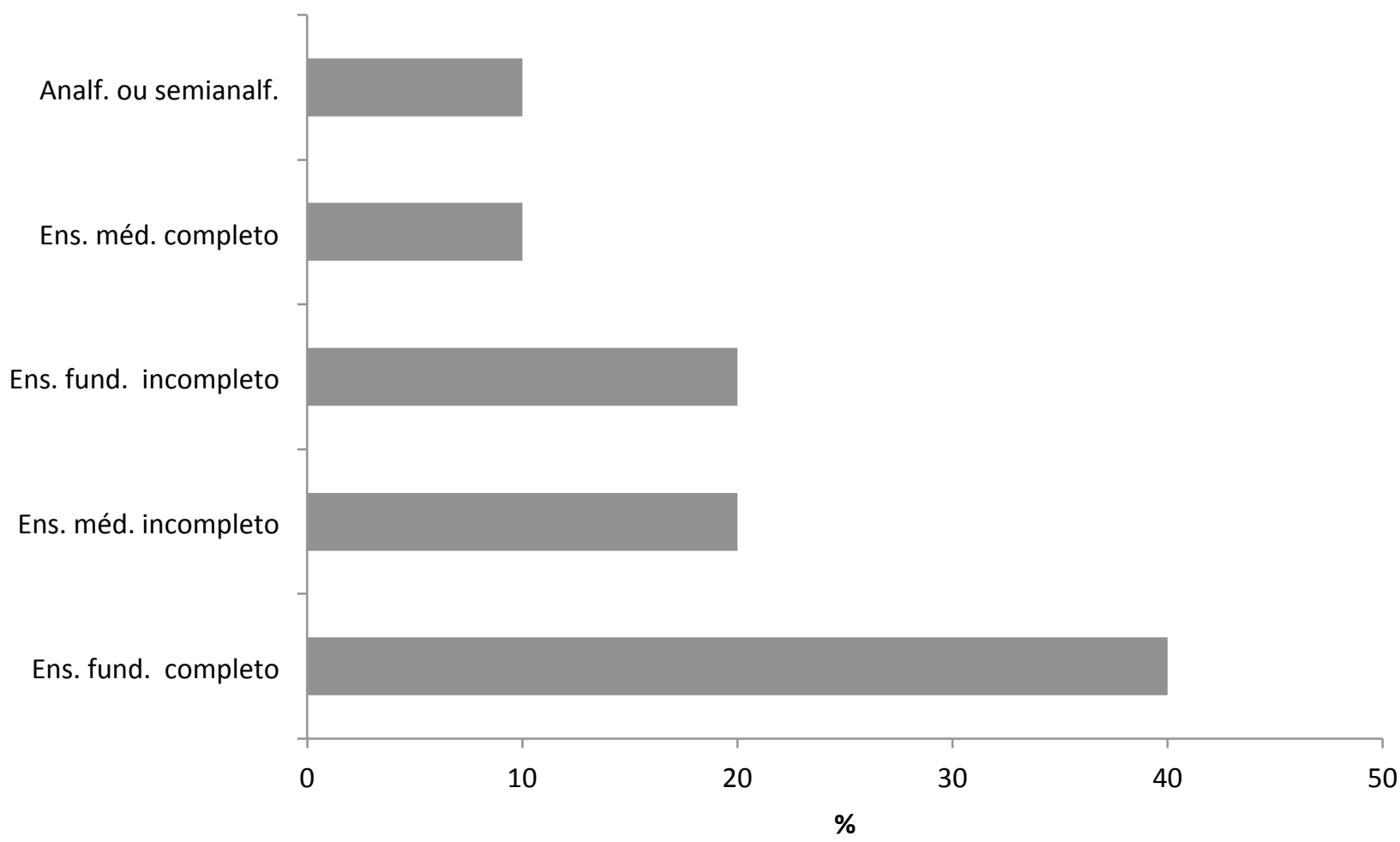

Figura 3. Escolaridade dos raizeiros. Macaíba, 2011.

Com relação ao tempo de trabalho no ramo das plantas medicinais, dos raizeiros entrevistados, 35,0 \% comercializa plantas medicinais entre seis e dez anos enquanto 23,0 \% trabalham no ramo há mais de 20 anos (Figura 3). 


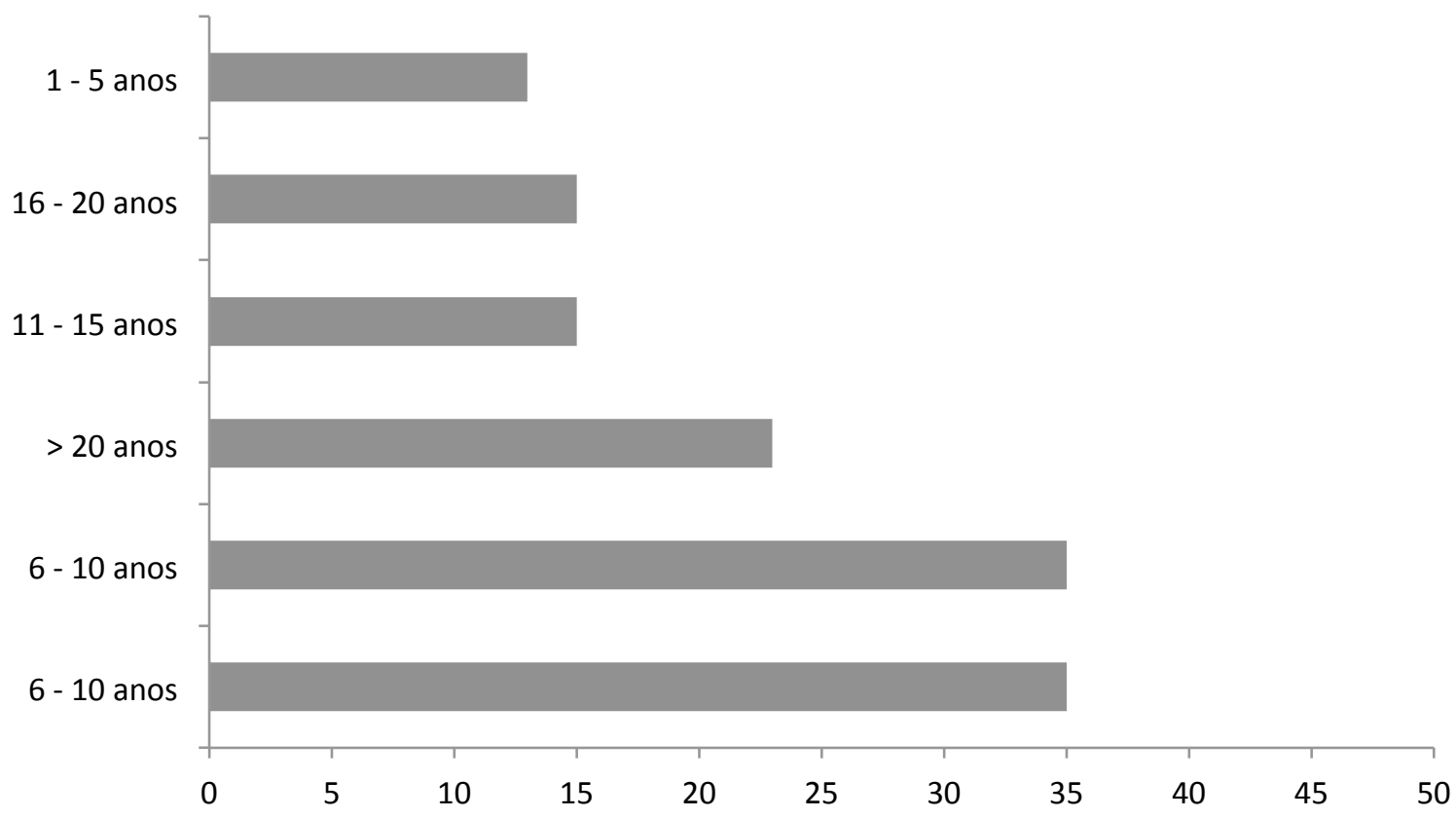

FIGURA 4. Tempo de trabalho dos raizeiros com plantas medicinais (A) e escolaridade dos raizeiros (B). Macaíba, 2011.

O conhecimento das propriedades terapêuticas das plantas medicinais foi adquirido, pela maioria dos entrevistados, por meio de informações transmitidas pelos seus ascendentes, principalmente pais e/ou avós (72,5 \%). A contribuição de livros e revistas foi pequena, tendo sido citada por 17,5 \% dos entrevistados (Figura 4). Valores semelhantes foram encontrados por Araújo et al. (2009) na cidade de Maceió, AL. Em trabalho realizado no município de Datas, MG, Arnous et al. (2005) observaram que $84,5 \%$ de pessoas entrevistadas aprenderam sobre a utilização das plantas medicinais com seus descendentes. Trabalhando em comunidades rurais da Bahia, Pinto et al. (2006), constataram o desinteresse dos jovens pela fitoterapia e/ou mesmo desconfiança de sua eficácia, o que poderá comprometer a manutenção de informações importantes sobre o uso destes recursos vegetais. 


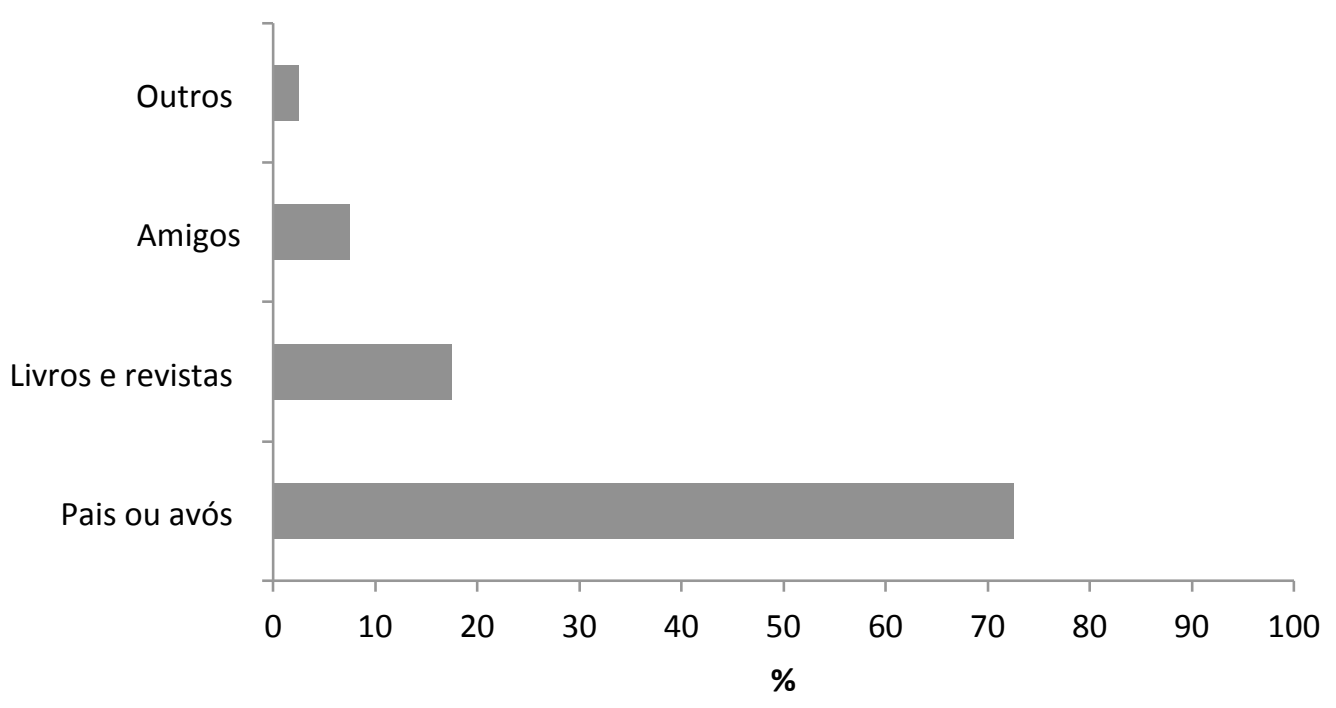

Figura 5. Forma de aquisição dos conhecimentos acerca das plantas medicinais. Macaíba, 2011.

Comparado com outros países, como França e Argentina, o interesse do brasileiro pela leitura ainda é pequeno, principalmente nas classes menos favorecidas, mesmo tendo sido registrado pequeno aumento ao longo dos anos (INSTITUTO PRÓ LIVRO, 2016). Sendo assim, outras fontes de informações concernentes à apropriação de conhecimentos, incluindo informações sobre plantas medicinais, sobressaem frequentemente.

Com relação à renda mensal, foi verificado que 85,0 \% dos raizeiros arrecadavam mais de um salário mensalmente com a venda das plantas, enquanto os $15,0 \%$ restantes afirmaram que o rendimento bruto mensal não chegava a um salário mínimo que, na época das entrevistas, era de $\mathrm{R} \$ 545,00$. Mesmo assim, na opinião de muitos entrevistados, a venda dos produtos gera um "bom dinheiro". Alves et al. (2007), estudando a realidade dos comerciantes e da comercialização de plantas medicinais em Campina Grande, $\mathrm{PB}$, verificou que os raizeiros desta cidade apresentam baixa renda, sendo que a maioria (70\%) recebia em torno de um salário mínimo.

É fato que a desconfiança da população no tocante à eficácia da fitoterapia associada à falta de cuidados na manipulação e armazenamento das plantas são fatores que diminuem a procura por estes produtos.

O percentual de raizeiros casados foi de $72,5 \%$ dos indivíduos entrevistados, valor bem superior ao de solteiros, que foi de $27,5 \%$. No que diz respeito à raça dos entrevistados, 55,0 \% dos raizeiros se disseram pardos, $35,0 \%$ brancos e 10,0 \% afirmaram-se negros. Estes valores concordam com a antiga e duradoura relação existente entre as plantas medicinais e descendentes de povos africanos e indígenas, importantes mantenedores do conhecimento das propriedades terapêuticas das plantas.

A maioria dos entrevistados $(90,0 \%)$ reside nas cidades nas quais a pesquisa foi realizada, com exceção de quatro raizeiros (10,0 \%) que afirmaram residir no município de Assu, RN. Com relação às cidades de origem dos raizeiros entrevistados, os naturais de Natal e das outras cidades nas quais foram realizadas as entrevistas perfazem $77,5 \%$, enquanto $17,50 \%$ afirmaram haver nascido em outras cidades do estado, como Governador Dix-Sept Rosado, Santo Antônio 
do Salto da Onça, Afonso Bezerra e Assu. Dois dos entrevistados (5,0 \%) afirmaram ser oriundos, um do município de Maceió e outro, de Marechal Deodoro, ambos do estado de Alagoas.

A

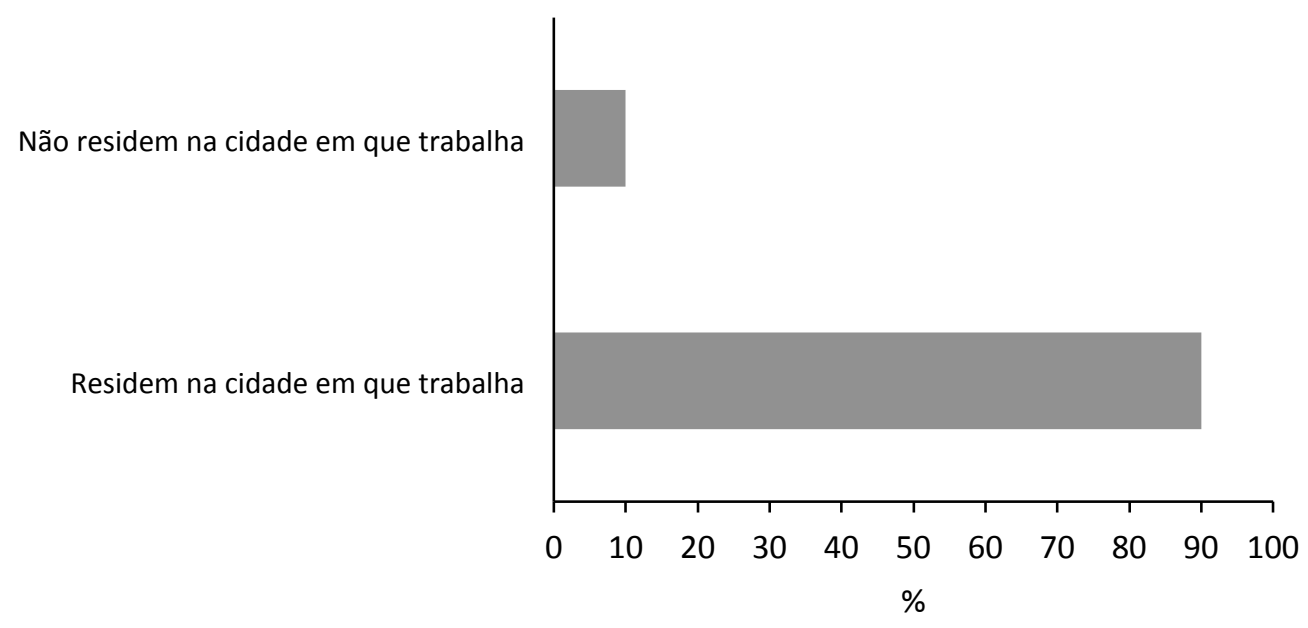

B

Nasceram em outras cidades

Nasceram na cidade onde trabalham

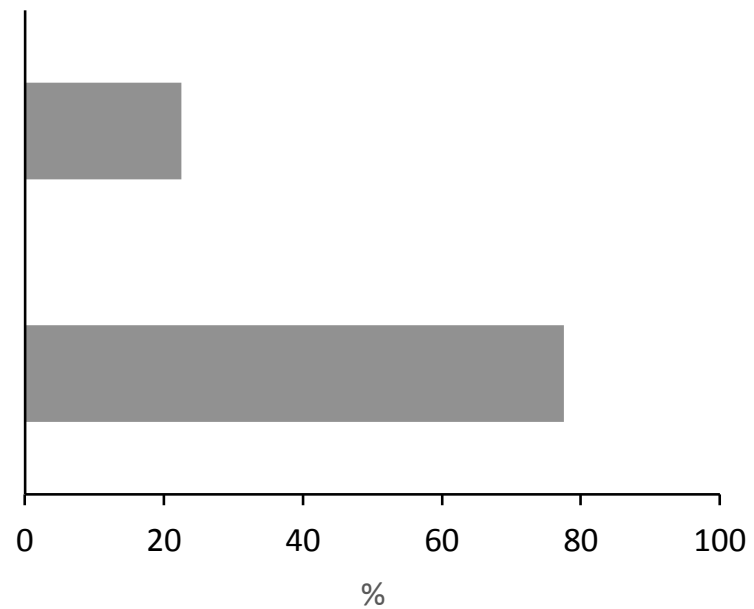

Figura 6. Percentual dos raizeiros que residem e que não residem na cidade em que trabalham (A) e percentual dos raizeiros que nasceram e que não nasceram na cidade em que trabalham (B). Macaíba. 
Ao final do texto deverão aparecer as REFERÊNCIAS, utilizando fonte calibri, tamanho da fonte 12 , alinhamento de parágrafo justificado e espaçamento de parágrafo de 6 pt (depois). Todas as referências colocadas no artigo deverão seguir a Norma da APA.

Dentre os entrevistados, 50,0\% afirmaram que a exposição direta ao sol é a forma de secagem adotada, enquanto $40,0 \%$ procedem a secagem ao sol e à sombra, alternadamente. Os restantes 10,0 \% responderam que realizam a secagem à sombra (FIGURA 6A). Em geral, a secagem de plantas medicinais ao sol não é recomendada, salvo rizomas e tubérculos que podem iniciar o processo de desidratação via exposição ao sol. A secagem de folhas e flores ao sol provoca endurecimento da camada superficial das células, perda de óleos essenciais e descoloração (HERTWIG, 1986). Quando expostas ao sol, as plantas murcham rapidamente, adquirindo mal aspecto, o que acaba afastando a clientela.

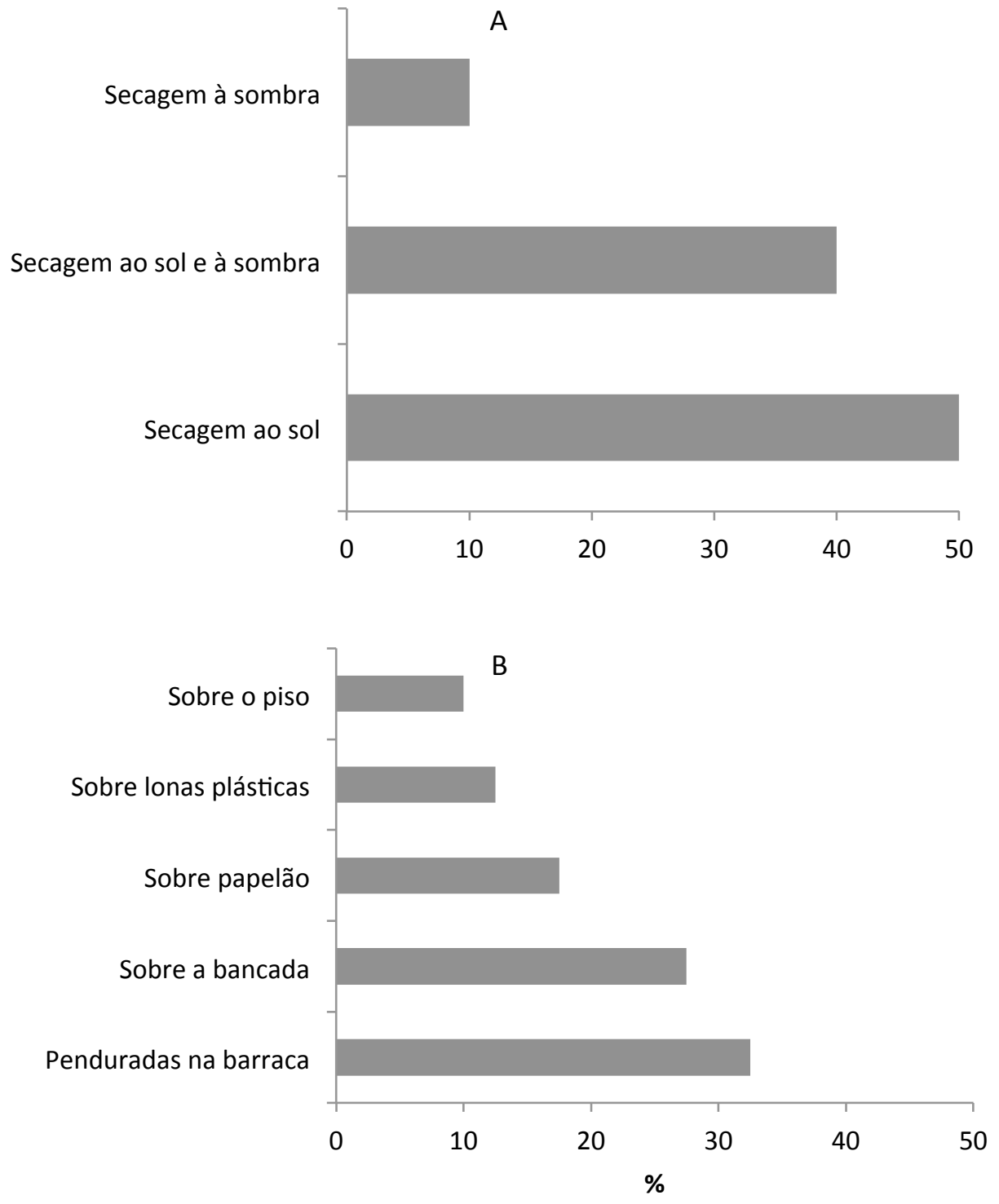

Figura 7. Forma de secagem (A) e Local de secagem (B) das plantas medicinais. Macaíba, 2011. 
Em relação ao local de secagem das plantas, 32,5 \% dos entrevistados disseram pendurar as plantas nas próprias barracas. Tal procedimento pode provocar perdas para o comerciante, pois há o risco de desprendimento e queda de partes das plantas. Outros $27,5 \%$ dos entrevistados disseram que o produto fica exposto na bancada da barraca. Há, ainda, os que dispõem as plantas sobre um papelão (17,5 \%). Dentre os demais, $12,5 \%$ afirmaram dispor as plantas sobre lonas plásticas e 10,0 \% disseram que as dispõem diretamente sobre o piso em suas residências (FIGURA 6B). O procedimento indicado por Martins et al. (2003) para a secagem das plantas é a sua disposição em locais frescos, sombreados, arejados, livre de pragas e cuidar para que não sejam amontoadas ou amassadas. Os autores sugerem a utilização de bandejas com moldura de madeira e fundo em tela plástica ou aço inoxidável em ambiente apropriado.

Quando questionados sobre o tempo de secagem das plantas, 62,5\% dos raizeiros responderam que o processo de dessecação do material leva de dois a três dias para ser completado, enquanto $37,50 \%$ afirmaram que o procedimento de secagem é concluído entre dois e quatro dias.

Salienta-se que secagens muito lentas, o que ocorre quando opta-se pela secagem natural em ambientes com umidade relativa do ar elevada e baixa temperatura, podem favorecer alterações na atividade enzimática, proliferação de fungos, fermentações e oxidações. No entanto, com temperaturas elevadas e umidades relativas do ar superiores a 50,0 \%, as quatro cidades nas quais foi realizado o estudo apresentam condições climáticas favoráveis à secagem natural.

Todos os raizeiros entrevistados afirmaram que, em geral, o tempo de armazenamento das plantas já desidratadas é inferior a um ano em função do produto ser comercializado antes deste período. Não há muitas informações sobre do tempo de conservação de plantas medicinais, mesmo porque isto depende da parte vegetal armazenada e/ou da qualidade do processo de secagem. Conforme Brito et al. (1999), o tempo de armazenamento não deve ser muito extenso pois as perdas dos princípios ativos podem ser grandes.

Ao serem questionados sobre o modo como, ao final do expediente de trabalho, 0 produto é guardado para ser reexposto no dia seguinte, 30,0\% dos entrevistados responderam que deixam o produto guardado em caixas de madeira, onde as plantas permanecem amontoadas umas sobre as outras. Outros 27,5 \% disseram mantê-las acondicionadas em sacos plásticos, muitas vezes os mesmos sacos plásticos em que são vendidas. Por fim, $17,50 \%$ afirmaram colocá-las em caixas de papelão, 15,0 \% as guardam em caixas plásticas e 10,0 \% organizam as plantas sem proteção alguma em algum local da banca de venda (FIGURA 7). Alves et al. (2007), em Campina Grande, PB, observou condições sanitárias de manutenção e armazenamento precárias para plantas medicinais comercializadas neste município, o que evidenciava possibilidade de contaminação microbiológica. O local de armazenamento, a forma como as plantas são armazenadas e as embalagens utilizadas exercem papeis determinantes. 0 local de armazenamento deve ser escuro, arejado, livre de animais e poeira, fatores essenciais para a manutenção dos princípios químicos viáveis por um maior espaço de tempo. Quando as plantas medicinais são guardadas e amontoadas em caixas, corre-se o risco de danificar o produto. Além do mais, quando as caixas são de papelão, não impedem a absorção de umidade. O material que deve ser utilizado para a estocagem das plantas varia de acordo com o volume e o tempo de armazenamento. Podem ser utilizados tonéis de madeira não aromática, potes de 
vidro, sacos de polietileno, polipropileno ou juta (MARTINS et al., 2003). Silva et al. (1999) verificaram que a qualidade pós-colheita de Achillea millefolium, Origanum vulgare e Petroselinum crispum é melhor preservada em embalagens de vidro por um período de até um ano.

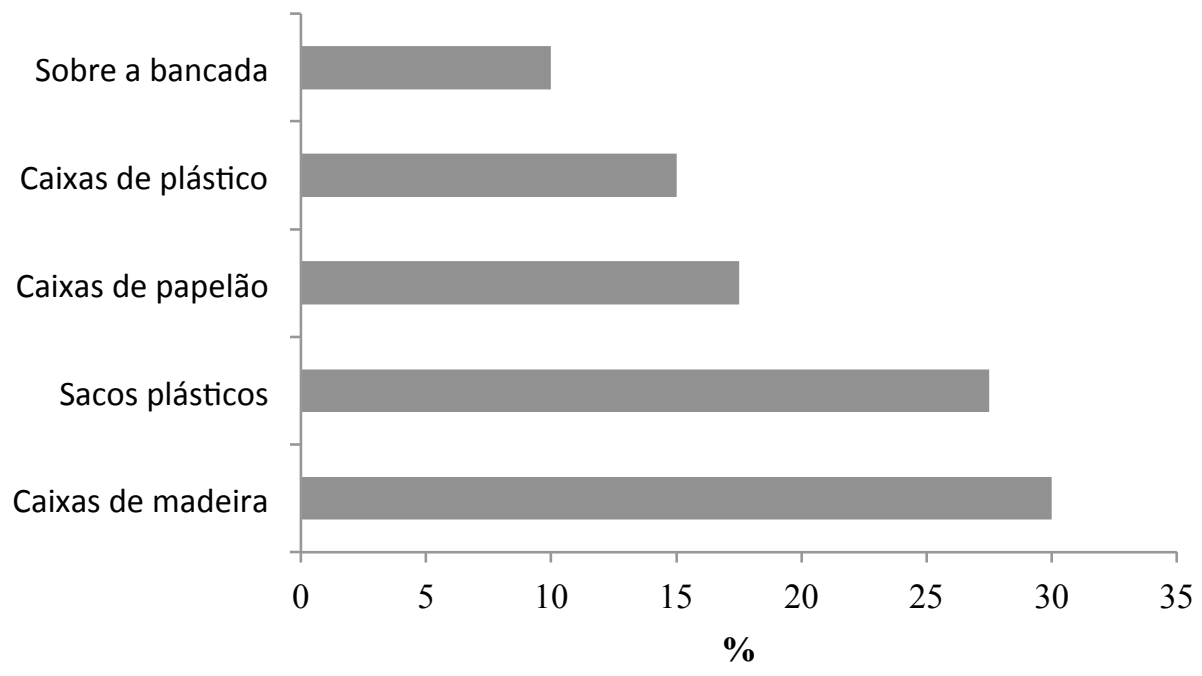

Figura 8. Forma de armazenamento das plantas após o expediente de trabalho. Macaíba, 2011.

No tocante à possibilidade de contato entre plantas de espécies distintas, $67,5 \%$ dos entrevistados responderam que, como geralmente as plantas são deixadas nas bancas de venda, geralmente o contato existe (Figura 8). Nestas condições pode haver interação entre os princípios químicos que, sob mudanças de temperatura, tem os seus efeitos alterados.

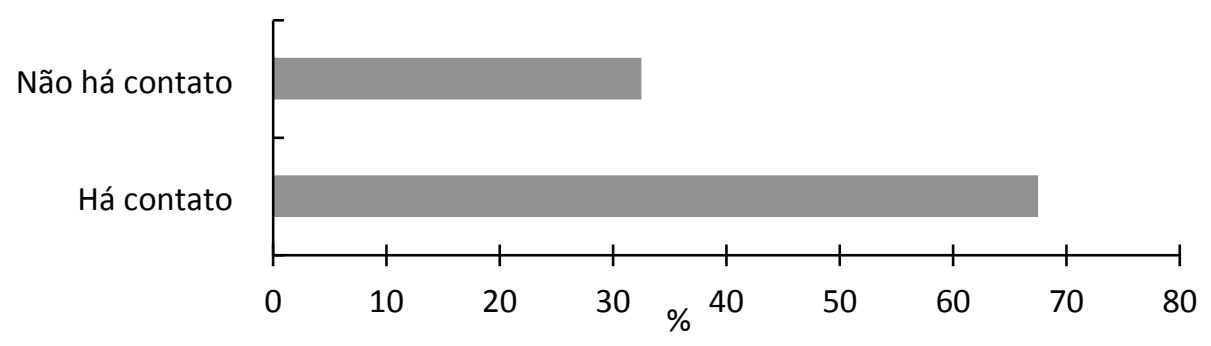

Figura 9. Contato entre plantas de espécies distintas. Macaíba, 2011.

Apesar da importância dos raizeiros para a preservação da tradição do uso das plantas medicinais no tratamento de inúmeras doenças, o que, diante da falência da saúde pública brasileira, mantém-se como importante recurso, senão a única alternativa para muitos, práticas inadequadas colocam em risco a eficácia dos tratamentos. Perda de princípios ativos em função de formas inadequadas de secagem, armazenamento e exposição a sol e umidade podem fazer 
com que potentes recursos curativos se transformem em mero placebo ou ainda fonte de contaminação.

\section{CONCLUSÕES}

A maior parte dos raizeiros de Natal, Santana do Matos, Ipanguaçu e Lagoa de Pedras era de cor parda, católica, apresentava no mínimo, o ensino fundamental incompleto e a renda mensal, obtida com a venda das plantas medicinais, ultrapassava um salário mínimo.

As formas de processamento pós-colheita e armazenamento de plantas medicinais adotados pelos raizeiros das quatro cidades escolhidas para o estudo mostraram-se inadequadas por comprometerem a qualidade do material comercializado e, por consequência, a saúde dos consumidores.

\section{AGRADECIMENTO}

Ao Cnpq, pela concessão de bolsas de iniciação científica às duas primeiras autoras.

\section{REFERÊNCIAS}

1. AlVES, R. R. da N; SILVA, A. de A. G. da; SOUTO, W. de M. S.; BARBOZA, R. R. D. (2007). Utilização e comércio de plantas medicinais em Campina Grande, PB, Brasil. Revista Eletrônica de Farmácia, 4 (2), 175-98.

2. MONTEIRO, J. M.; ARAÚJO, E. de L.; AMORIM, E. L. C.; ALBUQUERQUE, U. P. de (2010). Local Markets and Medicinal Plant Commerce: A Review with Emphasis on Brazil. Economy Botany, 64, 352-366.

3. ARAÚJO, A. C.; SILVA, J. P.; CUNHA, J. L. X. L.; ARAÚJO, J. L. O. (2009). Caracterização Sócioeconômico-cultural de Raizeiros e Procedimentos pós - colheita de Plantas Medicinais comercializadas em Maceió - AL. Revista Brasileira de Plantas Medicinais, 11 (1), 81-91.

4. ARNOUS, A. H.; SANTOS, A.S.; BEINNER, R. P. C. (2005). Plantas medicinais de uso caseiro conhecimento popular e interesse por cultivo comunitário. Revista Espaço para a Saúde, 6 (2), $1-6$.

5. BRITO, A. L. O.; PAIXÃO F. S.; REIS L. C.; SANTOS M. F.; CARVALHO R. M. C.; RIBEIRO S. S. (1999). Principais Cuidados no Cultivo, Manipulação e Consumo de Plantas Medicinais. Erros e Problemas mais Comuns. Disponível em: http://www.plantamed.com.br.

6. DANTAS, V. dos F.; DANTAS, I. C.; CHAVES, T. P.; FELISMINO, D. de C.; SILVA, H.; DANTAS, G. D. dos (2008). Análise das garrafadas indicadas pelos raizeiros na cidade de Campina Grande-PB. Biofar, 3 (1), 7-13.

7. DANTAS, I. C.; GUIMARÃES, F. R. (2006). Perfil dos raizeiros que comercializam plantas medicinais no município de Campina Grande, PB. Revista de Biologia e Ciências da Terra, 6 (1), 39-44. 
8. ETHUR, L. Z.; JOBIM, J. C.; RITTER, J. G.; OLIVEIRA, G.; TRINDADE, B. S. (2011). Comércio formal e perfil de consumidores de plantas medicinais e fitoterápicos no município de Itaqui - RS. Revista Brasileira de Plantas Medicinais, 13, (2), 121-128.

9. FReitAS, A. V. L. de; COElHO, M. de F. B.; AZEVEDO, R. A. B. de; MAIA, S. S. S. (2012). Os raizeiros e a comercialização de plantas medicinais em São Miguel, Rio Grande do Norte, Brasil. Revista Brasileira de Biociências, 10 (2), 147-156.

10. HERTWIG, I.F.V. (1986). Plantas aromáticas e medicinais. São Paulo: Ícone.

11. IBGE (2010). Censo Populacional. Disponível em: http://www.ibge.gov.br/

12. INSTITUTO PRÓ LIVRO (2016). Relatos da leitura no Brasil. Disponível em: http://www.publishnews.com.br.

13. MAGALHÃES, P. M. (1997). O caminho medicinal das plantas. Campinas: RZM Press.

14. MARTINS, E.R.; CASTRO, D. M. de; CASTELLANI, D. C.; DIAS, J. E. (2003). Plantas medicinais. Viçosa: UFV.

15. MelO, J.G.; NASCIMENTO, V. T. do; AMORIM, E. L. C. de; ANDRADE LIMA, C. S. de; ALBUQUERQUE, U. P. de. (2017). Qualidade de produtos à base de plantas medicinais comercializados no Brasil: castanha-da-índia (Aesculus hippocastanum L.), capim-limão (Cymbopogon citratus (DC.) Stapf) e centela (Centella asiatica (L.) Urban) (2007). Acta Botanica Brasilica, 21 (1), 27-36.

16. PINTO, E. P. P.; AMOROZO, M. C.; FURLAN, A. (2006). Conhecimento popular sobre plantas medicinais em comunidades rurais de mata atlântica - Itacaré, BA, Brasil. Acta Botanica Brasílica, 20 (4), 751-62.

17. PNUMA (2002). Convention on Biological Diversity. Disponível em: http:// www.biodiv.org.

18. ROCHA, F. A. G. da; MEDEIROS, F. G. M. de; SILVA, J. L. A. da (2010). Diagnóstico da qualidade sanitária de plantas medicinais comercializadas no município de Currais Novos, RN. Holos, 26 (2), 71-79.

19. SILVA, F.; CASALI, V. W. D.; LIMA, R. R.; ANDRADE, N. J. Qualidade pós-colheita de Achillea millefolium L., Origanum vulgare L. e Petroselinum crispum (Miller) A.W. Hill em três embalagens (1999). Revista Brasileira de Plantas Medicinais, 2 (1), 37-41, 1999. 